\title{
Bullying reduction and subjective wellbeing: The benefits of reduced bullying reach far beyond the victim
}

\author{
Roberta Ann Heydenberk · Warren Robert Heydenberk
}

\begin{abstract}
Numerous studies have revealed the relationship between bullying and an increased risk of depression, and suicidal ideation (Nansel, Overpeck, Saluja \& Ruan, 2004; Card \& Hodges, 2008; Harris, 2009; Wang, Iannotti, \& Nansel, 2009: Lenci \& Matuga, 2010). The World Health Organization's longitudinal, multi-national study of children's subjective wellbeing found that school climate and the quality of children's relationships are the most significant factors in predicting wellbeing (Klocke, Clair, \& Bradshaw, 2014). Decades of research have revealed the benefits of healthy levels of subjective wellbeing (SWB). One of the major factors affecting subjective wellbeing is the quality of an individual's social interactions (Diener, 2016). This threeyear study of 1218 th and 5th-grade students in 16 classrooms within eight suburban/urban schools assessed changes in students' subjective wellbeing or happiness before and after implementation of a bullying prevention/intervention program. Three subgroups were identified: bullies, victims, and bystanders. As bullying declined in all of the three subgroups, significant positive prosocial pretest to posttest changes were identified on two Centers for Disease Control Bullying Compendium Modified Aggression Subscales (the Bullying Subscale and the Cooperative Caring Subscale). Statistically significant gains in subjective wellbeing were found within the largest group: the bystander (witness) student group, during each year of the threeyear study. Although there were positive changes in measures of SWB in bullies and victims during the three-year study, the changes were not statistically significant.
\end{abstract}

Keywords: bully, victim, bystander, subjective wellbeing, focus, affect, depression, school climate, bullying reduction

\section{Literature review}

\subsection{Subjective wellbeing}

Subjective wellbeing research focuses on "the study of what lay people might call happiness" (Diener, Oishi, \& Lucas, 2003, p. 404). Despite concerns that happiness may diminish motivation, the research shows that happy people are more likely to be productive, active citizens across their lifespan, healthier with stronger immune systems, and less likely to suffer from chronic diseases, among other positive outcomes (Diener \& Tay, 2012; Diener, 2016). The study of "subjective wellbeing comprises the scientific analysis of how people evaluate their lives-both at the moment and for longer periods of time" (Diener et al., 2003, p. 404). Healthy levels of happiness or of subjective wellbeing (SWB) are strongly related to physical and mental health (Diener \& Seligman, 2004). Positive social support and emotional intelligence are strong predictors of healthy levels of SWB (Gallagher \& Vella-Brodrick, 2008). In fact, "social relationships have been 
found to have a strong association with mortality...[and] show a larger effect on longevity than factors such as physical activity, body mass index and/or drug treatment for hypertension" (Diener \& Chan, 2011, p. 28).

Daily positive or negative interactions are the most powerful predictors of positive or negative affect scores (McCullough, Huebner, \& Laughlin, 2000). In fact, social support and social resources are "more strongly related to SWB than [are] material resources" (Diener \& Fujitia, 1995, p. 28). Numerous "demographic factors such as health, income, educational background and marital status account for only a small amount of variance in wellbeing measures" (Diener, Oishi \& Lucas, 2003, p. 406). Social support, and positive social interaction predict healthy levels of subjective wellbeing and they are essential to physical and mental health.

A multinational, longitudinal study conducted by the World Health Organization collected data on adolescents from 1983. The multilevel analysis confirms variation in effects of individual characteristics on SWB at the country level. No such effects were found for the country level variables included, such as GDP/economic factors and youth unemployment. "This is a remarkable result. It indicates that it is not the economy (GDP) or the level of spending on family policies which can foster child wellbeing. Rather, it is the country and school climate that influence the way individual characteristics influence child subjective wellbeing" (Klocke, Clair, \& Bradshaw, 2014, p. 3). Other researchers have confirmed that economic variables and inequality are not the most significant factors impacting children's subjective wellbeing. Instead, "It is the nature of children's relationships" (Lee \& Yoo, 2014, p. 151) that strongly predicts healthy levels of subjective-wellbeing.

\subsection{The prevalence of bullying}

Although bullying rates among youth vary, depending on factors such as age, cultural and social norms, as well as the way researchers define bullying, a study of bullying that included a comprehensive list of bullying behaviors revealed that $67 \%$ of all young people had experienced at least one type of bullying aggression defined in the study (Peterson \& Ray, 2006). Other studies have found bullying rates as high as $75 \%$, with one quarter of a typical young population experiencing bullying with relative frequency, and approximately one-third of students feeling unsafe at school because of bullying (Peterson \& Ray, 2006). Comprehensive national measures of bullying in the United States reveal that more than 35\% of adolescents are verbally bullied and approximately $13 \%$ are physically bullied with relative frequency (Wang, Iannotti, \& Nansel, 2009).

While bullying and violence may be associated with low income schools or urban schools, it is a more pervasive and endemic problem. Students living in rural environments are at risk of experiencing significant bullying. Researchers found that "of 15 measures of violence ... none showed a significantly lower prevalence among rural teens. In fact, rural teens were more likely than urban or suburban teens to have carried a weapon ... rural teens [were] equally or more likely than suburban or urban teens to be exposed to violent activities" and to use drugs (Mink, Moore, Johnson, Probst, \& Martin, 2005, p. 4).

\subsection{The impact of bullying}

In contrast to the beneficial outcomes of positive social support, which include healthy levels of SWB, negative social interactions such as bullying have far-reaching deleterious impacts on mental and physical health, relationships, cognitive functioning, and productivity (Harris, 2009). For instance, bullying increases the risks of depression, school failure, and the developmental issues associated with depression in children, and studies of adults who were bullied in their 
youth reveal lasting negative effects (Carlisle \& Rofes, 2007). Lasting negative impacts, including shame, anxiety, and difficulty in relationships, compound the problem for victims (Carlisle \& Rofes, 2007). Increased developmental impacts on children include "weakened development of social competencies which may harm future social and work prospects" (Jensen-Campbell, Knack, Waldrip, \& Ramirez, 2009; Due et al., 2005, p. 129).

Bullying researchers warn us that "the problem of bullying among youth has become an international concern. Studies on school aged children in the United States, Australia, England, Germany, and Scotland confirm that bullying is associated with adverse outcomes for both the victim and the bully, including poorer social, emotional, and physical health; these psychological challenges may persist into later adolescence and adulthood" (Nansel, Overpeck, Saluja, \& Ruan, 2004 , p. 730). Furthermore, victimization is associated with "academic maladjustment, low school enjoyment, school avoidance, absenteeism [and] low academic achievement" (Card \& Hodges, 2008, p. 454). Victimized students have negative changes in brain function which impair their ability to focus and learn (Card \& Hodges, 2008, p. 454). Adolescents are "especially susceptible to the health effects of negative social interactions" (Due et al., 2005, p. 130).

Not only is bullying prevalent, its effects on victims are long-lasting. Research on a group of more than 6,000 adult males revealed that "those exposed to bullying in school were at a significantly increased risk of having been diagnosed with depression between the ages of 31-50 years." Long duration and high intensity of bullying were the variables which predicted depression later in life (Lund et al, 2009). Furthermore, when former victims have their own children, they are often overprotective and sheltering, which "may inhibit the development of conflict resolution skills and social skills in their children-placing the children at heightened risk of becoming the next generation of victims" (Smokowski \& Kopasz, 2005, p. 105).

Involvement in bullying, either as a bully or as a victim, increases a young person's risk "of dying of any of three main causes of mortality among young people-suicide, homicide, or accidents" (Srabstein \& Piazza, 2008, p. 229). Both bullying and victimization are associated with later suicide attempts and completed suicides (Sourander et al., 2007). Bullies are more likely than non-bullying peers to suffer from depression and suicidal ideation (Klomeck et al., 2007, p. 43). Young bullies are likely to have varied conduct disorders, low school commitment and more significant health problems than non-bullying youth (Srabstein \& Piazza, 2008). Bullies are at "higher risk of suffering from self-inflicted, accidental and perpetuated injuries, abusing overthe-counter medications, hurting animals and people on purpose, using a weapon that could hurt someone seriously and being frequently absent from school" (Srabstein \& Piazza, 2008, p. 228). Bullies are also at higher risk for drug abuse, setting fires, self-injury, and carrying weapons (Srabstein \& Piazza, 2008).

Bullying, ostracism, or social exclusion at any age has negative impacts. Bullying is a significant factor in predicting the presence of adolescent depression. Young people who are involved in bullying, either as a perpetrator or as a victim, are more than twice as likely to be among those who suffer from depression than their uninvolved peers (Saluja et al., 2004). Bullying and peer victimization are also associated with suicidal ideation, completed suicides, and suicide attempts: "The more types of victimization, the higher the risk of depression and suicidality among both genders" (Klomek, Marrocco, Kleinman, Schonfeld, \& Gould, 2007, p. 43). Depression is a "substantial and largely unrecognized problem among children that warrants an increased need and opportunity for identification and intervention" (Saluja et al., 2004, p. 762). 


\subsection{Bystander/witness effects}

Bullying is too often conceptualized as action between two individuals, the bully and his victim. Unfortunately, the deleterious human effects transcend the bully-victim dyad. It appears that no one in a social community is untouched by the presence of bullying. Simply witnessing bullying puts bystanders at risk of psychological and social disorders. Research reveals that the negative impacts of witnessing bullying include fear, guilt, and depression (Janson, Carney, Hazler, \& Oh, 2009). A study of bystanders in 14 public schools revealed that witnessing bullying was associated with bystanders' greater concurrent and subsequent use of alcohol and drugs, as well as bystander trauma and anxiety (Rivers, Poteat, Noret, \& Ashurst, 2009). Bystanders who are subjected to "negative peer influence" and "those who change their opinions to match their friend's engage in a range of risky behaviors and subsequently experience more instabilities in close friendships, decreased popularity and higher levels of depression" (Juvonen \& Galvan, 2009, p. 306).

Bystanders who witness bullying may be "intimidated and fearful" (Whitted \& Dupper, 2005, p. 171). Although not directly targeted, bystanders are often distracted, which may make concentration on academic tasks difficult. Furthermore, bystanders often report feeling guilty years later. When bystanders are asked to "recall witnessing bullying, their levels of psychological distress (as measured by the Impact of Event Scale, self-reports of trauma levels, heart rate changes and skin conductance measurements) were unexpectedly high and were comparable to levels of distress experienced by combat veterans diagnosed with posttraumatic stress disorder" (Janson \& Hazler, 2004, p. 239).

Relatively high levels of bullying occur in grades 5-8 (Janson, Carney, Hazler, \& Oh, 2009), therefore early school-based intervention strategies may provide hope for bullying reduction and raise students' subjective wellbeing.

\section{Purpose of study}

This three-year study explored the relationship between reduced bullying and students' subjective wellbeing in a suburban/urban school environment. Students' perceptions and their use of bully strategies were also assessed and elucidated.

\section{Participants and treatment}

The bully intervention/prevention program included 1,218 students in 16 classrooms (eight 4thgrade classrooms and eight 5th-grade classrooms) in a suburban/urban school district adjacent to a major urban center on the east coast of the United States. Three teacher trainers provided 9 hours of bullying awareness/reduction training to all students and teachers in hourly time blocks over a period of 2 months for a total of 9 training hours per classroom. The three trainers held degrees in conflict resolution or related areas and had provided numerous successful trainings prior to this study. All classroom teachers of the student participants engaged in the study were volunteers, and they were encouraged to be active participants in the training sessions. Infusion of conflict positive strategies into content area curricula was also encouraged, and examples were presented during the training sessions. Classrooms were observed during the investigation period to determine compliance.

Interactive/participatory class meetings, which provided a vehicle for specific activities, were a central focus of the anti-bullying program. As bullying was defined, discussed, and identified, students participated in meetings to design social contracts (listing and discussing prosocial behaviors to help students respect and support each other in their classrooms). Empathy and 
respect were given attention, and the development of affective vocabulary was achieved through classroom check-in meetings. Students responded to an "I message" sentence stem- "I feel with an affective vocabulary sheet (feeling words) daily. Meetings were used to help students recognize and understand emotions and develop affective vocabulary, assertive communication skills and empathy. Metacognitive anger management strategies were introduced, such as STAR: Stop, Think, Ask (customized questions for each student's specific patterns of communication), and Reflect/Resolve for impulsive aggression/bullying, Additional age appropriate strategies which had been found to be effective in previous research (Heydenberk \& Heydenberk, 2007a, $2007 \mathrm{~b}$ ) for effective prosocial communication and conflict resolution were taught during ongoing weekly sessions.

At the onset of the investigation, researchers asked students to self-identify either as bully, victim, or a bystander ("most of the time I am...."). Because of their limited definitions of bullying, along with a tendency to deny bullying, the bullying of siblings was discussed with students. Students are often more comfortable discussing bullying behaviors in the sibling context (Heydenberk \& Heydenberk, 2015). Consequently, the students candidly answered questions about their own interpersonal bullying behavior patterns. Within the sample of 1,218 students, $28 \%$ identified as having been the victim of a bully, $7 \%$ identified themselves as a bully and $65 \%$ identified themselves as a bystander.

The study employed a pretest-posttest design for intervention classroom students which included measures of subjective wellbeing (SWB) and the Centers for Disease Control (CDC) compendium of bullying/aggression scales. The 7-point SWB scale used in this study was a simplified version of the D-T scale (Delighted-Terrible scale). Although single item measures "tend to be less reliable" (Diener, 2009, p. 14) than multiple item measures, the D-T scale has an estimated $65 \%$ valid variance and stable validity when compared to other measures of SWB (Diener, 2009). To assure clarity, students (identified as bullies, victims, or bystanders) were also asked to circle a related graphic indicating their sense of wellbeing, using the neutral, smiling, and frowning face graphics adjacent to the affect vocabulary.

Students were instructed to close their eyes and think about how happy/unhappy they feel "most of the time" in all areas of their lives. The central graphic was neutral, with a straight line for the mouth expression (score $=0$ ). The three graphics to the left of the neutral face graphic indicated increasing levels of happiness (smiles with scores $=1$ to 3 points), and the three graphics to the right indicated increasing levels of unhappiness (frown - scores $=-1$ to -3 ).

The instrument used for assessment of aggression and bullying was the Centers for Disease Control's Modified Aggression Scale. The scale is composed of four subscales which measure students' fighting rates, bullying behavior, anger, and cooperative/caring interactions. The internal consistencies of the scales range from .60 to .83. All questions provided a 5-point Likert scale for student responses.

The Caring/Cooperation Subscale (.60) is comprised of eight items, such as:

I helped other students solve a problem.

I told other students how I felt when they upset me.

The Anger Subscale (internal consistency .75) contains five items, such as:

I got into a physical fight because I was angry (reverse coded).

I was mean to someone when I was angry (reverse coded).

The Bullying Subscale (internal consistency .83) contains four items, such as:

I teased other students (reverse coded).

I threatened to hit or hurt another student (reverse coded). 
The Fighting Subscale (internal consistency .73) is comprised of five items, such as: I hit.

Each response had a possible range of 0 (no opportunity) to 4 points per question.

Negative behaviors were reverse coded. For example:

I hit back when someone hit me first.

Positive, prosocial behaviors were forward coded. For example:

I walked away from a fight.

Negative behaviors were reverse coded (e.g., I called students names $=4$ points for " $1-2$ times" to 1 point for the " 5 or more times" choice). Positive behaviors were coded directly (e.g., I helped other students $=0$ for "no opportunity" to 4 points for the " 5 or more times" choice). Therefore, higher scores indicate higher rates of prosocial behaviors and skill use. Pretests and posttests were coded with students' classroom number, and students' initials were coded, and all data/responses were assessed as either bully, victim, or bystander group means within each school. The CDC scales and the SWB responses were analyzed as group means at the classroom level with a 2 tailed t-test / alpha.05.

At the onset of the study, bullying was defined, elucidated and discussed, by providing examples of unidirectional, unprovoked physical aggression, and relational aggression. At the end of the study, students were asked to assess changes in bullying rates by estimating the number of bullying incidents they experienced (in the role of witness/bystander, victim, or bully) for one typical week prior to the bullying prevention program and again one week after the program concluded, approximately eight weeks later.

A customized scale with questions of high content validity asked students to rate their use of the various intervention and prevention strategies and the group processes employed during the bullying prevention/intervention lessons. These posttest-only subscales asked students to rank intervention and prevention strategies. Students were asked to identify: 1 ) which strategies were the most helpful, or used most frequently, 2) which strategies were used beyond the classroom setting, 3) which strategies changed how students think about bullying, 4) and which strategies helped students understand bullying and understand classmates. Finally, students responded to several questions about changes in their sense of school safety, connectedness, and their ability to focus on academic tasks.

\section{Results and discussion}

The findings from the sample of 1,218 students from 16 (4th and 5th grade) elementary school classrooms per year for a total of 48 classroom sessions revealed a $48 \%$ mean (M) reduction in bullying rates (standard deviation/ $\mathrm{SD}=7.3$ ), and statistically significant prosocial behavioral gains (one-tailed t-test /alpha.05) on two of the CDC Modified Aggression Subscales, the Bullying Subscale and the Cooperative/Caring Behavior Subscale. Positive but nonsignificant gains (alpha .05) were assessed from pretest to posttest on the Anger Subscale and the Fighting Subscale.

Within the sample of 1,218 students, 29\% (314 students) were self-identified victims of routine bullying at the time of the pretest, $7 \%$ (85 students) were self-identified bullies, and $65 \%$ of the sample (792 students) were self-identified as bystanders. The majority of the self-identified victims of bullying reported fewer incidents of bullying at the end of the training program. Bully victimization rates were reduced by approximately $48 \%$ (mean bullying rate reduction $=48 \%$, standard deviation $=7.3$ ) in the victim group. 
Students rated class meetings as the most important bullying program component (citing enhanced ability to speak to peers, enhanced ability to stand up for themselves/others, and enhanced understanding and friendships among students). Metacognitive strategies for impulse control (e.g., the STAR activity: Stop, Think, Ask, Resolve/Review) ranked as the second most important intervention strategy. Emotional awareness activities and social norming activities (designing a respectful classroom/social contact) were rated as the third and fourth favorite strategies among students. The majority of students reported:

- feeling safer in the classroom (65\% agreed or strongly agreed)

- worrying less about bullying (78\% agreed or strongly agreed)

- enhanced ability to stand up for themselves or others (87\% agreed or strongly agreed)

- feeling happier about coming to school (80\% agreed or strongly agreed)

- transfer of skills/using skills beyond the school setting (79\% agreed or strongly agreed).

Students felt that bullying had been reduced ( $82 \%$ agreed or strongly agreed). Over $75 \%$ of students indicated that it was easier to focus or pay attention at the time of the posttest, when bullying was reduced.

As shown in Table 1 below, students were asked to respond to a measure of subjective wellbeing in the form of a 7-point Likert scale with numbers and graphics ranging from (-3) very sad/unhappy to $(+3)$ very happy.

Table 1. Pretest and posttest group means and standard deviation scores (M/SD) on measures of subjective wellbeing

\begin{tabular}{llccc}
\hline SWB & & $\begin{array}{c}\text { Bystander group } \\
\text { mean and standard } \\
\text { deviation }\end{array}$ & $\begin{array}{c}\text { Victim group mean } \\
\text { and standard } \\
\text { deviation }\end{array}$ & $\begin{array}{c}\text { Bully group mean } \\
\text { and standard } \\
\text { deviation }\end{array}$ \\
\hline Year 1 & Pre-test & $2.41 / 0.124$ & $1.46 / 0.157$ & $2.32 / 0.200$ \\
& Post-test & $2.58^{*} / 0.083$ & $1.55 / 0.138$ & $2.42 / 0.233$ \\
Year 2 & Pre-test & $2.42 / 0.132$ & $1.45 / 0.220$ & $2.38 / 0.127$ \\
& Post-test & $2.65^{*} / 0.981$ & $1.57 / 0.155$ & $2.45 / 0.183$ \\
Year 3 & Pre-test & $2.40 / 0.201$ & $1.48 / 0.045$ & $2.41 / 0.087$ \\
& Post-test & $2.63^{*} / 0.659$ & $1.49 / 0.058$ & $2.43 / 0.177$ \\
\hline
\end{tabular}

*Significant difference /Alpha .05

All students: bullies, victims, and bystanders, had positive gain scores during the investigation, although the mean gains for victims and bullies were not statistically significant. Bystanders had the highest mean SWB pretest scores. At the time of the posttest, the bystanders' mean SWB score revealed a statistically significant gain (2-tailed t-test/alpha .05). Students in the victim category had the lowest mean SWB pretest scores and posttest scores. Although all three student groups (bullies, victims, bystanders) showed positive gains in subjective wellbeing and their perceptions about their ability to focus, the bystander group gains were the highest and consistently significant during the 3-year investigation.

Decades of research have revealed the potentially devastating long-term impact of bullying on victims (Srabstein \& Piazza, 2008). When studying factors affecting SWB, positive daily events relate most significantly to levels of life satisfaction and happiness (McCullough, Huebner, \& Laughlin, 2000). The World Health Organization (Klocke et al., 2014) found that school climate and positive relationships impact wellbeing more significantly than GDP/economic factors in countries all over the world. In this study, the lowest SES (socioeconomic status) school had the 
lowest bullying scores and the highest SWB scores on pretests and posttests throughout the 3year study. Additionally, the school's exemplary academic achievements reflected the positive SWB and sense of school community. The highest SES school had the highest level of bullying and the lowest SWB on pretests for 2 years of the study.

This study of the relationship between bullying and SWB, along with a recent and growing body of bullying research, has identified significant risks to the wellbeing of bystanders as well as to bully/victim dyads (Janson, Carney, Hazler, \& Oh, 2009). Since bullying is a negative daily event in most schools, it is not surprising that this study illustrates the power of bullying to degrade the SWB of the entire school community, not just that of victims and bullies. This study also illustrates the potential power of simple social norming strategies, through democratic class meetings, and skill building such as check-ins, I messages, and the STAR strategy to reduce bullying and improve students' SWB, ability to focus, and feelings about their lives. Such strategies can be infused into the academic curriculum without losing instructional time from subject matter learning.

Although the victims and bullies showed positive SWB gains, the victim group and bully group SWB gains were less significant than the gains made by the bystander group. The victims and bullies may warrant additional individual interventions and targeted support, such as cognitive behavioral therapy (Grills-Taquechel, Polifroni, \& Pane, 2010), in addition to whole class treatments. However, changing group norms and transforming school culture, as was accomplished in this study, may have significant positive impact on all three student groups.

Positive affect or SWB isn't simply a pleasant construct; SWB has significant impacts on students' ability to focus on academic tasks and to learn. Fear, guilt and other forms of negative affect may have far-reaching effects on cognition and creative thinking (Harris, 2009). Positive affect also increases prosocial behavior and enhances the ability to attend and to form connections with others (Sekerka \& Fredrickson, 2008). Positive affect creates an upward spiral of psychological and physical health, creativity, and academic productivity for all members of a school community.

The interdependence of the cognitive and affective domains has long been recognized. Given the devastating effects bullying has on bystanders, bullies, and victims, attention should be directed to reduction of bullying and fostering positive SWB in classrooms if optimal emotional and cognitive growth of students is to be attained.

\section{Authors}

Roberta Ann Heydenberk

Lehigh University

wrh2@lehigh.edu

Warren Robert Heydenberk

Lehigh University

\section{Publishing Timeline}

Received 3 February 2016

Accepted 17 April 2017

Published 9 June 2017

\section{References}


Card, N., \& Hodges, E. (2008). Peer victimization among school children: Correlations, causes, consequences, and considerations in assessment and intervention. School Psychology Quarterly, 23, 451-461. https://doi.org/10.1037/a0012769

Carlisle, N., \& Rofes, E. (2007). School bullying: Do adult survivors perceive long term effects? Traumatology, 13(1), 16-26. https://doi.org/10.1177/1534765607299911

Diener, E. (2009). The science of well being: The collected works of Ed Diener. Social Indicators Research Series, 37, 1-270. https://doi.org/10.1007/978-90-481-2350-6 1

Diener, E., \& Chan, M. (2011). Happy people live longer: Subjective well being contributes to health and longevity. Applied Psychology: Health and Well Being, 3(1), 1-43. https://doi.org/10.1111/j.1758$\underline{0854.2010 .01045 . x}$

Diener, E., \& Fujuitia, F. (1995). Methodological pitfalls and solutions in satisfaction research. In M. J. Sirgy \& A. C. Samli (Eds.), New dimensions in marketing/quality-of-life research (pp. 27-46). Westport, CT: Greenwood Press.

Diener, E., Oishi, S., \& Lucas, R. E. (2003). Personality, culture, and subjective well being: Emotional and cognitive evaluations of life. Annual Review of Psychology, 54, 403-425. https://doi.org/10.1146/annurev.psych.54.101601.145056

Diener, E., \& Seligman, M. (2004). Beyond money: Toward an economy of well-being. Psychological Science in the Public Interest, 5(1), 1-31. https://doi.org/10.1111/j.0963-7214.2004.00501001.x

Diener, E., \& Tay, L. (2016). New frontiers: Societal measures of subjective well- being for input into policy. In L. Bruni \& P. Porta (Eds.), Handbook of research methods and applications in happiness and quality of life. Northampton, MA: Elgar.

Due, P., Holstein, B., Lynch, J., Diderichsen, F., Gabhain, S., Scheidt, P., Currie, C., \& The Health Behaviour in School-Aged Children Bullying Working Group (2005). Bullying and symptoms among school-aged children: international comparative cross sectional study in 28 countries. European Journal of Public Health 15(2), 128-132. https://doi.org/10.1093/eurpub/cki105

Due, P., Merlo, J., Harel-Fisch, Y., Damsgaard, M. T., soc, M. S., Holstein, B. E., ... \& de Matos, M. G. (2009). Socioeconomic inequality in exposure to bullying during adolescence: a comparative, crosssectional, multilevel study in 35 countries. American Journal of Public Health, 99(5), 907-914. https://doi.org/10.2105/AJPH.2008.139303

Gallagher, E., \& Vella-Brodrick, D. (2008). Social support and emotional intelligence as predictors of subjective well-being. Personality and Individual Differences, 44, 1551-1561. https://doi.org/10.1016/j.paid.2008.01.011

Grills-Taquechel, A. E., Polifroni, R., \& Pane, H. T. (2010). Methods for assessing and treating bullyvictim problems for individual children and adolescents. In E. M. Vernberg \& B. K. Biggs (Eds.), Preventing and treating bullying and victimization: Integrative and evidence-based practices. New York, NY: Oxford University Press.

Harris, M. (2009). Bullying, rejection and peer victimization: A social cognitive neuroscience perspective. New York, NY: Springer.

Heydenberk, W., \& Heydenberk, R. (2007a). More than manners: Conflict resolution in primary level classrooms. Early Childhood Education Journal, 35, 119-126. https://doi.org/10.1007/s10643-007-0185-4

Heydenberk, R., \& Heydenberk, W. (2007b). The conflict resolution connection: Increasing school attachments in cooperative classroom communities. Reclaiming Children and Youth, 16(3), 18-22.

Heydenberk, R., \& Heydenberk, W. (2015). From risk to resilience: Understanding and preventing bullying and bias. In C. Del Felice, A. Karako, \& A. Wisler (Eds.), Peace education evaluation: Learning from experience and exploring prospects (pp. 85-102). Charlotte, NC. Information Age.

Janson, G., Carney, J., Hazler, R., \& Oh, I. (2009). Bystanders' reactions to witnessing repetitive abuse experiences. Journal of Counseling and Development, 87(3), 319-326. https://doi.org/10.1002/j.1556$\underline{6678.2009 . t b 00113 . x}$

Janson, G., \& Hazler, R. (2004). Trauma reactions of bystanders and victims to repetitive abuse experiences. Violence and Victims, 19(2), 239-255. https://doi.org/10.1891/vivi.19.2.239.64102 
Jensen-Campbell, L. A., Knack, J. M., Waldrip, A., \& Ramirez, M. (2009). The importance of personality and effortful control processes and victimization. In M. Harris (Ed.). Bullying, rejection and peervictimization: A social neurocognitive perspective (pp. 103-123). New York, NY: Springer.

Juvonen, J., \& Galvan, A. (2009). Bullying as a means to foster compliance. In M. Harris (Ed.), Bullying, rejection and peer victimization: A social cognitive neuroscience perspective (pp. 299-318). New York, NY: Springer.

Klomek, A., Marrocco, F., Kleinman, M., Schonfeld, I., \& Gould, M. (2007). Bullying, depression, and suicidality in adolescents. Journal of the American Academy of Child and Adolescent Psychiatry, 46(1), 4049. https://doi.org/10.1097/01.chi.0000242237.84925.18

Kochenderfer-Ladd, B., \& Pelletier, M. (2008). Teachers' views and beliefs about bullying: Influences on classroom management strategies and students' coping with peer victimization. Journal of School Psychology, 46, 431-453. https://doi.org/10.1016/j.jsp.2007.07.005

Lee, B., \& Yoo, M. (2015). Family, school and community correlates of children's subjective well-being: An international comparative study. Child Indicators Research, 8(1), 151-175.

Lenci, M., \& Matuga, J. (2010). The lifetime bully: Investigating the relationship between adolescent bullying and depression in early adulthood. Journal of School Counseling, 8(7), 7-7.

Lund, R., Nielsen, K., Hansen, D., Kriegbaum, M., Molbo, D., Due, P., \& Christensen, C. (2009). Exposure to bullying at school and depression in adulthood: A study of Danish men born in 1953. European Journal of Public Health, 19(1), 111-116. https://doi.org/10.1093/eurpub/ckn101

McCullough, G., Huebner, S., \& Laughlin, J. (2000). Life events, self-concept, and adolescents' positive subjective well-being. Psychology in the Schools, 37(3), 281-289. https://doi.org/10.1002/(SICI)15206807(200005)37:3<281::AID-PITS8>3.0.CO;2-2

Mink, M. D., Moore, C. G., Johnson, A., Probst, J. C., \& Martin, A. (2005). Violence and rural teens: Teen violence, drug use, and school-based prevention services in rural America. Washington, DC: U.S. Department of Health and Human Services, Office of Rural Health Policy.

Nansel, T., Overpeck, C., Saluja, M., \& Ruan, W. (2004). Cross national consistency in the relationship between bullying behaviors and psychosocial adjustment. Archives of Pediatrics $\mathcal{E}$ Adolescent Medicine, 158, 730-736. https://doi.org/10.1001/archpedi.158.8.730

Peterson, J., \& Ray, K. (2006). Bullying and the gifted: Victims, perpetrators, prevalence and effects. In M. J. Harris (Ed.), Bullying, rejection, and peer victimization: A social cognitive neuroscience perspective (pp. 148-168). New York, NY: Springer. https://doi.org/10.1177/001698620605000206

Rivers, I., Poteat, V., Noret, N., \& Ashurst, N. (2009). Observing bullying at school: The mental health implications of witness status. School Psychology Quarterly, 24(4), 211-223. https://doi.org/10.1037/a0018164

Rosen, P., Milich, R., \& Harris, M. (2009). Why is everybody always picking on me? Social cognition, emotional regulation and chronic peer victimization in children. In M. Harris (Ed.), Bullying, rejection and peer victimization: A social cognitive neuroscience perspective (pp. 79-100). New York, NY: Springer.

Saluja, G., Iachan, R., Scheidt, P., Overpeck, M., Sun, W., \& Giedd, J. (2004). Prevalence of and risk factors for depressive symptoms among young adolescents. Archives of Pediatrics and Adolescent Medicine, 158, 760-765. https://doi.org/10.1001/archpedi.158.8.760

Sekerka, L., \& Fredrickson, B. (2008). Establishing positive emotional climates to advance organizational transformation. In N. Ashkanasy \& C. Cooper (Eds.), Research companion to emotion in organizations (pp. 531-544). Cheltenham, England: Edgar Elgar. https://doi.org/10.4337/9781848443778.00046

Smokowski, P. R., \& Kopasz, K. H. (2005). Bullying in school: An overview of types, effects, family characteristics, and intervention strategies. Children and Schools Journal, 27(2), 101-110.

https://doi.org/10.1093/cs/27.2.101

Sourander, A., Jensen, P., Rönning, J., Elonheimo, H., Niemelä, S., Helenius, H., .. \& Almqvist, F. (2007). Childhood bullies and victims and their risk of criminality in late adolescence: The Finnish from a boy to a man study. Archives of Pediatrics and Adolescent Medicine, 161(6), 546-552. https://doi.org/10.1001/archpedi.161.6.546

Srabstein, J., \& Piazza, T. (2008). Public health, safety and educational risks associated with bullying behaviors in American Adolescents. International Journal of Adolescent Medical Health, 20(2), 223-233. h 
Tay, L., \& Diener, E. (2011). Needs and subjective well-being around the world. Journal of Personality and Social Psychology, 101(2), 354-365.

Wang, L., Iannotti, R., \& Nansel, T. (2009). School bullying among adolescents in the United States: Physical, verbal, relational, and cyber. Journal of Adolescent Health, 45(4), 368-375.

https://doi.org/10.1016/j.jadohealth.2009.03.021

Whitted, K., \& Dupper, D. (2005). Best practices for preventing or reducing bullying in schools. Children and Schools, 27(3), 167-175. https://doi.org/10.1093/cs/27.3.167 